\title{
Twelve Weeks of Aerobic Exercise at the Lactate Threshold Improves Autonomic Nervous System Function, Body Composition, and Aerobic Performance in Women with Obesity
}

\author{
Hun-Young Park ${ }^{1,2}$, Won-Sang Jung ${ }^{2}$, Jisu Kim ${ }^{1,2}$, Hyejung Hwang ${ }^{2}$, Kiwon Lim ${ }^{1,2,3, *}$ \\ 'Department of Sports Medicine and Science, Graduate School, Konkuk University, Seoul, ${ }^{2}$ Physical Activity and Performance Institute and ${ }^{3}$ Department of Physical \\ Education, Konkuk University, Seoul, Korea
}

Background: The present study examined the effects of a prolonged exercise intervention at the lactate threshold (LT) on body composition, aerobic performance, and the autonomic nervous system (ANS) in women with obesity.

Methods: A total of 36 obese Korean women aged 36 to 55 years (mean \pm standard deviation, $44.8 \pm 5.2$ years) were randomly assigned to a control group (CON, $n=18)$ or an experimental group (EXP, $n=18)$; and EXP underwent aerobic exercise training three times a week at a heart rate corresponding to the LT (HR_LT) for 12 weeks. All dependent variables (body composition, aerobic performance, and ANS function parameters) were evaluated before and after training.

Results: Compared with the CON group, the EXP group showed significant improvement in body composition (body weight, -4.57 vs. $-2.40 \mathrm{~kg}$; body mass index, -1.79 vs. $-0.96 \mathrm{~kg} / \mathrm{m}^{2}$; \%body fat, $-4.63 \mathrm{vs.}-1.41$; fat-free mass, 3.24 vs. $-0.08 \mathrm{~kg}$ ), aerobic performance (oxygen consumption at LT, $5.74 \mathrm{vs} .0 .12 \mathrm{~mL} / \mathrm{kg} / \mathrm{min}$; maximal oxygen consumption, 5.41 vs. $2.14 \mathrm{~mL} / \mathrm{kg} / \mathrm{min}$; treadmill speed at HR_LT, $1.40 \mathrm{vs.} 0.29 \mathrm{~km} / \mathrm{hr}$; bicycle load at HR_LT, 18.62 vs. 4.52 w; and ANS function (mean RR, 50.83 vs. -15.04 ms; standard deviation of NN intervals, 5.08 vs. $-0.55 \mathrm{~ms}$; root mean square of successive differences, $6.42 \mathrm{vs}$. $1.87 \mathrm{~ms}$; total power, $0.34 \mathrm{vs} .0 .10 \mathrm{~ms}^{2}$; high frequency, 0.32 vs. $-0.04 \mathrm{~ms}^{2}$; low frequency/high frequency, -0.09 vs. 0.01 ).

Conclusion: Aerobic exercise at the LT for 12 weeks is a practical method of improving body composition, aerobic performance, and ANS function for women with obesity.

Key words: Aerobic exercise, Body composition, Aerobic performance, Autonomic nervous system, Obesity

Received November 4, 2019 Reviewed December 9, 2019

Accepted December 18, 2019

*Corresponding author

Kiwon Lim

https://orcid.org/0000-0003-3222-1783

Department of Physical Education, Konkuk University, 120 Neungdong-ro, Gwangjin-gu, Seoul 05029, Korea

Tel: +82-2-450-3827

Fax: +82-2-452-6027

E-mail: exercise@konkuk.ac.kr
Obesity is an accumulation of excess fat, caused by energy imbalance between excess food intake and the calories consumed. ${ }^{1}$ According to a report by the World Health Organization in 2014, more than 1.9 billion people, or $39 \%$ of the world's adult population, are overweight and 13\%, or 6 million people, are obese. ${ }^{2}$ As for the prevalence of obesity in Korea, the male obesity rate decreases with age (32\% in 20 s, $43.9 \%$ in 30 s, $39.6 \%$ in 40 s, $41.5 \%$ in
50 s, $36.9 \%$ in 60 s, and $24.0 \%$ in more than 70 s). On the other hand, women's obesity rate increases rapidly with age $(15.0 \%$ in 20 s, $18.6 \%$ in 30 s, $22.3 \%$ in 40 s, $29.3 \%$ in 50 s, $36.6 \%$ in 60 s, and $37.3 \%$ in more than $70 \mathrm{~s}) .{ }^{3}$ This suggests that the obesity rate increases by age in women and 20 to 40 years old women who have a relatively low prevalence of obesity need long-term and continuous treatment for obesity. 
Three methods of preventing and treating obesity are available: pharmacotherapy, surgery, and combined diet and exercise. Of these, pharmacotherapy and surgery can offer instant weight loss, but due to costs and side effects, they are limited to specific patients in clinical aspects. ${ }^{4,5}$ However, a combination of dietary and exercise therapies has the effect of increasing basal metabolism by activating fat utilization through increased fat and energy consumption as well as weight and body-fat reduction. ${ }^{6}$

The most recommended exercise modality for prevention and treatment of obesity is aerobic activity, preferably in the form of regular activities such as walking, biking, jogging, etc. ${ }^{7}$ Aerobic exercise is most effective in reducing fat and body weight when performed three to five times a week, with an exercise intensity of $50 \%$ to $85 \%$ of maximal oxygen consumption $\left(\mathrm{VO}_{2 \max }\right)$ or $60 \%-90 \%$ of maximal heart rate $\left(\mathrm{HR}_{\max }\right)$ and an exercise time of 45-60 minutes. ${ }^{3,7}$ A wide range of exercise intensity settings using $\mathrm{VO}_{2 \max }$ or $\mathrm{HR}_{\max }$ results in different levels of aerobic and anaerobic metabolic responses during the same exercise load according to the maximum exercise performance of each individual. Menzel and Hilberg $^{8}$ recommended an anaerobic threshold (AT) intensity for each individual as the optimal exercise intensity for weight loss. Among typical methods of determining AT are the lactate threshold (LT), which is based on blood lactate levels, and ventilator threshold (VT), which is measured by respiratory gas. ${ }^{9}$ The LT and VT do not typically appear at the same time, and the LT generally tends to appear before the VT. In addition, the LT indicates a point of rapid change in blood lactate levels, and is considered an efficient and practical method with less subjective bias for determining an AT compared with the VT.9,10

Weight loss through aerobic exercise results in reduced blood cholesterol, improved hypertension, increased insulin sensitivity, reduced risk of cardiovascular disease, and improved aerobic exercise capacity. ${ }^{11,12}$ Aerobic exercise also has reduced levels of leptin, insulin, cortisol, and thyroid stimulating hormone during submaximal exercise, ${ }^{13-15}$ and it increases the activity of the vagus nerve, reduces resting heart rate, activates the parasympathetic nervous system (PNS), and provides for autonomic control. ${ }^{12,16-18}$

Tests of heart rate variability (HRV) are widely used in clinical practice to examine the relationship between obesity and the autonomic nervous system (ANS). It is a noninvasive and reliable eval- uation method that can quantitatively evaluate the activity of the sympathetic and PNSs. ${ }^{12,19,20}$ The ANS function is closely related to obesity; a sustained increase in sympathetic nervous system activity at rest causes a decrease in basal metabolism, an increase in body weight, and obesity. ${ }^{19,21,22}$ Salivary cortisol is also positively correlated with HRV, which represents the sympathetic-parasympathetic balance. ${ }^{12}$ The ANS response, evaluated by HRV and salivary cortisol, can be used as an important index for obesity prevention and treatment, and it is necessary to examine the relationship between physiological changes induced by aerobic exercise and ANS changes. Kim et al. ${ }^{12}$ reported that 12 weeks of combined aerobic and resistance exercise improves HRV and reduces mental stress in older women with obesity. An exercise program was found to be effective in reducing body fat in elderly women with obesity with similar body composition and cultural patterns in East Asian countries. Park et al. ${ }^{23}$ verified that a dietary intervention of $70 \%$ of recommended dietary allowance and exercise training corresponding to the heart rate at the LT for 12 weeks effectively improved body composition, aerobic performance, and stress. These findings show that moderate aerobic exercise can improve ANS function and prevent and treat obesity. ${ }^{24}$ However, whether prolonged aerobic exercise at the LT affects ANS function in women with obesity remains unclear. In this study, we hypothesized that prolonged aerobic exercise at the LT would improve ANS function and reduce obesity in middle-aged women. We carried out a randomized trial to investigate the influences of aerobic exercise training at the LT for 12 weeks on body composition, aerobic performance, and ANS function in women with obesity.

\section{METHODS}

\section{Participants}

The study participants were 44 obese 36- to 55-year-old Korean women (mean \pm standard deviation, $44.8 \pm 5.2$ years) with a body mass index $(\mathrm{BMI})>25 \mathrm{~kg} / \mathrm{m}^{2}$ and a history of participating in only low levels of aerobic activity. Applicants' menopausal status was not assessed. Six participants dropped out due to health problems and personal circumstances during the training period, leaving 36 active participants. The participants consented by signature, after sufficient explanation of the experimental conditions and ac- 
Table 1. Participants' characteristics

\begin{tabular}{lrrc}
\hline Variable & CON $(\mathrm{n}=18)$ & $\operatorname{EXP}(\mathrm{n}=18)$ & $P$ \\
\hline Age $(\mathrm{yr})$ & $45.89 \pm 5.78$ & $44.78 \pm 5.21$ & 0.549 \\
Height $(\mathrm{cm})$ & $158.39 \pm 4.23$ & $159.17 \pm 3.45$ & 0.550 \\
Weight $(\mathrm{kg})$ & $70.62 \pm 6.94$ & $70.96 \pm 3.76$ & 0.854 \\
BMI $\left(\mathrm{kg} / \mathrm{m}^{2}\right)$ & $28.16 \pm 2.64$ & $28.03 \pm 1.62$ & 0.858 \\
Free fat mass $(\mathrm{kg})$ & $42.37 \pm 4.16$ & $42.58 \pm 2.26$ & 0.854 \\
Fat mass $(\%)$ & $34.45 \pm 2.96$ & $35.52 \pm 1.31$ & 0.175 \\
\hline
\end{tabular}

Values are presented as mean \pm standard deviation.

CON, control group; EXP, experimental group; BMI, body mass index.

knowledging an understanding of the possible adverse effects, and were randomly assigned to a control group $(\mathrm{CON} ; \mathrm{n}=18)$ or experimental group (EXP; aerobic exercise group, $n=18$ ) using a computerized random number generator (Table 1). Thirty-six of the participants completed the study and only their data were used in the analyses. All procedures of the study were approved by the Institutional Review Board of Konkuk University (IRB No. 7001355201812-HR-288) in Korea and they were conducted according to the Declaration of Helsinki.

\section{Study design}

The experimental design involved a 3-day pre-testing session, 12 weeks of intervention, and a 3-day post-testing session. On the first pre- and post-testing days, all participants fasted for more than 8 hours. After stabilization, saliva was collected between 7:00 and 9:00 AM. Body composition and HRV were then measured. On the second pre- and post-test day, a graded exercise test (GXT) was performed on a treadmill to evaluate $\mathrm{VO}_{2 \max }, \mathrm{VO}_{2}$ corresponding to the LT $\left(\mathrm{VO}_{2}\right.$ LT), $\mathrm{HR}_{\max }$, and $\mathrm{HR}$ corresponding to the LT (HR_LT). On the third pre- and post-test days, all participants performed an aerobic exercise on a treadmill and a bicycle for 30 minutes each at the HR_LT, and the treadmill speed and bicycle load at the HR_LT were measured. Dietary intake and daily activities were investigated once every 4 weeks to minimize the effect of extrinsic variables on dependent variables.

Participants in the EXP group carried out aerobic exercises on treadmills and bicycles for 30 minutes each (total 60 minutes) at the HR_LT. In contrast, members of the CON group did not carry out any exercise intervention. All exercises were performed three times a week at a constant temperature of $22^{\circ} \mathrm{C}$ and humidity of $60 \%$, for a total of 12 weeks.

\section{Dietary intake}

All participants were requested to record their meals (i.e., type, amount, and ingredients of food) once every 4 weeks both before and during the 12-week intervention period, and nutritionists monitored their records monthly. However, we did not supply specific instructions for dietary treatment because the purpose of this study was not to confirm the effect of dietary treatment. Total caloric intake was analyzed by selecting the records twice each weekday and once each weekend at various points throughout the study. Nutritional analyses were performed using the Computer Applied Nutrition Analysis Program, according to Korea Nutrition Facts from the Korea Food and Drug Administration in the Ministry for Health, Welfare and Family Affairs, Republic of Korea.

\section{Daily activity}

To investigate the amount of daily activity other than the prescribed exercise of all the subjects, daily caloric consumption was estimated using a fitness band (Polar M400; Polar, Finland).

\section{Height and body composition}

Height and body composition parameters (body weight, free-fat mass, percent of body fat, and BMI) were measured using bioelectrical impedance analysis equipment (Inbody 770; Inbody, Seoul, Korea).

\section{Aerobic performance}

Aerobic performance was assessed using two methods. First, it was evaluated based on changes in $\mathrm{VO}_{2 \max }$ and $\mathrm{VO}_{2}$ LT measured by GXT using an automatic breathing gas analyzer (K4B2; Cosmed, Pavona, Italy). As the subjects were obese, the protocol was initiated at $3.6 \mathrm{~km} / \mathrm{hr}$ and the speed was increased by $1.2 \mathrm{~km} / \mathrm{hr}$ every $2 \mathrm{~min}$ utes. Second, exercises were performed on a treadmill and bicycle for 30 minutes each in accordance with the HR_LT. Mean values for the speed on the treadmill and the load on the bicycle during 30 minutes of exercise were measured.

\section{ANS function}

HRV and salivary cortisol were measured to examine changes in ANS function after 12 weeks of exercise intervention. After approximately 30 minutes of rest, four pads were placed on the wrists and 
ankles using an HRV analyzer (CANS-3000; LAXTHA, Daejeon, Korea), and the participant's HRV was measured in a resting condition. The measured HRV parameters were as follows: average of all $\mathrm{R}$-wave-to-R-wave intervals (mean R-wave-to-R-wave; mean RR), standard deviation of successive differences (SDNN) and root mean square of successive differences (RMSSD) were analyzed as time-domain methods, and total power (TP), low frequency (LF), high frequency $(\mathrm{HF})$, and the LF/HF ratio were measured as frequency-domain methods. Salivary cortisol was analyzed by an enzyme-linked immunosorbent assay using the ER HS Salivary Cortisol kit (Salimetrics, State College, PA, USA).

\section{Statistical analysis}

Means and standard deviations were calculated for all dependent variables. The normality of distribution of all outcome variables was verified using the Kolmogorov-Smirnov test. A two-way analy-

(A)

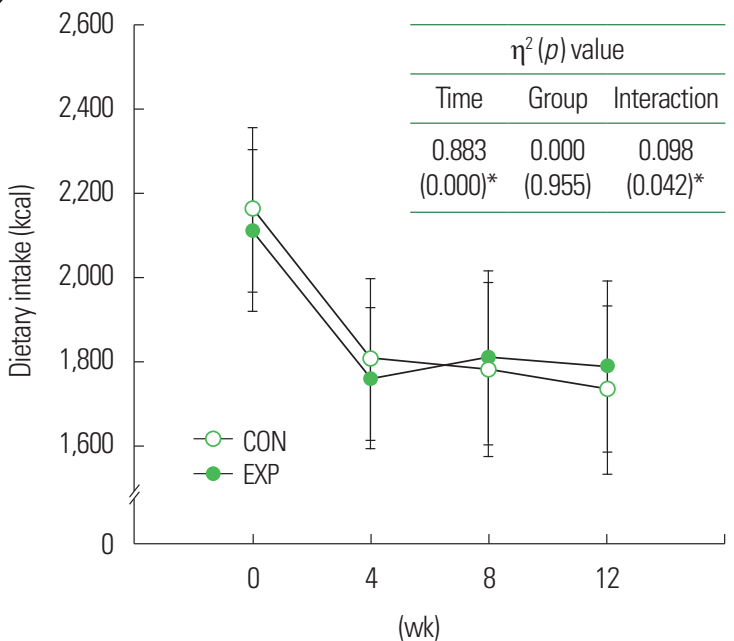

sis of variance with repeated measures on the "time" factor was used to analyze the effects of exercise intervention for 12 weeks on each dependent variable. Post-hoc Bonferroni testing was used to identify within-group changes over time. Clinically meaningful change was assessed by calculating the mean change and $95 \%$ confidence interval. All analyses were carried out using IBM SPSS version 23.0 (IBM Corp., Armonk, NY, USA). A priori, the level of significance was set at 0.05 .

\section{RESULTS}

As shown in Fig. 1, a significant interaction is apparent between the two groups for dietary intake $\left(P=0.042, \eta^{2}=0.098\right)$. However, daily activity did not show any significant interactions between the two groups. The post-hoc analysis for the group difference at time points in dietary intake with significant interactions found no sig-

B

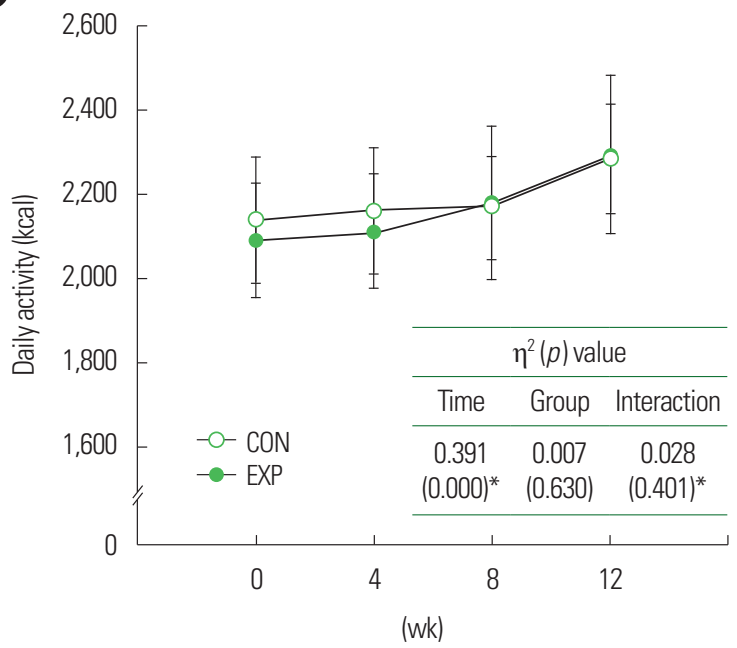

Figure 1. Changes of dietary intake (A) and daily activity (B) during the intervention. Mean and standard deviation for dietary intake and daily activity with main analysis of variance in control group (CON) and experimental group (EXP). * Significant interaction or main effect.

Table 2. Body composition before and after training with main analysis of variance results

\begin{tabular}{|c|c|c|c|c|c|c|c|c|c|}
\hline \multirow{2}{*}{ Measure } & \multicolumn{3}{|c|}{ CON } & \multicolumn{3}{|c|}{ EXP } & \multicolumn{3}{|c|}{$\eta^{2}(P)$} \\
\hline & Before & After & Mean change (95\% Cl) & Before & After & Mean change (95\% CI) & Time & Group & Interaction \\
\hline Body weight (kg) & $70.62 \pm 6.94$ & $68.22 \pm 7.04$ & $-2.40(-3.39 \text { to }-1.41)^{\dagger}$ & $70.96 \pm 3.76$ & $66.39 \pm 3.56$ & $-4.57(-6.34 \text { to }-2.79)^{\dagger}$ & $0.607(0.000)^{\ddagger}$ & $0.005(0.683)$ & $0.130(0.031)^{\ddagger}$ \\
\hline $\mathrm{BMI}\left(\mathrm{kg} / \mathrm{m}^{2}\right)$ & $28.16 \pm 2.64$ & $27.20 \pm 2.60$ & $-0.96(-1.37 \text { to }-0.56)^{\dagger}$ & $28.03 \pm 1.62$ & $26.23 \pm 1.69$ & $-1.79(-2.48 \text { to }-1.11)^{\dagger}$ & $0.611(0.000)^{\ddagger}$ & $0.017(0.443)$ & $0.124(0.035)^{\ddagger}$ \\
\hline Fat-free mass (kg) & $42.37 \pm 4.16$ & $42.29 \pm 4.36$ & -0.08 (-0.69 to 0.54$)$ & $42.58 \pm 2.26$ & $45.81 \pm 2.46$ & $3.24(2.09 \text { to } 4.38)^{\dagger}$ & $0.438(0.000)^{\ddagger}$ & $0.077(0.102)$ & $0.461(0.000)^{\ddagger}$ \\
\hline Body fat $(\%)$ & $34.45 \pm 2.96$ & $33.04 \pm 3.01$ & $-1.41(-2.56 \text { to }-0.26)^{*}$ & $35.52 \pm 1.31$ & $30.88 \pm 2.31$ & $-4.63(-5.97 \text { to }-3.30)^{\dagger}$ & $0.606(0.000)^{\ddagger}$ & $0.017(0.453)$ & $0.304(0.000)^{\ddagger}$ \\
\hline
\end{tabular}

Values are presented as mean \pm standard deviation.

${ }^{*} P<0.05 ;{ }^{\dagger} P<0.001$ vs. before training; ${ }^{*}$ Significant interaction or main effect.

CON, control group; EXP, experimental group; $\mathrm{Cl}$, confidence interval; BMI, body mass index. 
nificant difference between the groups.

A significant difference was found between the two groups for body weight $\left(P=0.031, \eta^{2}=0.130\right)$, BMI $\left(P=0.035, \eta^{2}=0.124\right)$, fat-free mass $\left(P<0.001, \eta^{2}=0.461\right)$, and \%body fat $(P<0.001$, $\left.\eta^{2}=0.304\right)$ (Table 2). Post-hoc analyses found significant decreases in bodyweight (EXP, $-4.57 \mathrm{~kg}[-6.34$ to $-2.79 \mathrm{~kg}]$; CON, $-2.40 \mathrm{~kg}$ $[-3.39$ to $-1.41 \mathrm{~kg}] ; P<0.001)$, BMI $\left(\mathrm{EXP},-1.79 \mathrm{~kg} / \mathrm{m}^{2}[-2.48\right.$ to $\left.-1.11 \mathrm{~kg} / \mathrm{m}^{2}\right]$; CON, $-0.96 \mathrm{~kg} / \mathrm{m}^{2}\left[-1.37\right.$ to $\left.-0.56 \mathrm{~kg} / \mathrm{m}^{2}\right] ; P<$ 0.001), and \%body fat (EXP, $-4.63 \%$ [-5.97\% to $-3.30 \%]$; CON, $-1.41 \%[-2.56 \%$ to $-0.26 \%] ; P<0.05)$. Fat-free mass (EXP, $3.24 \mathrm{~kg}$ [2.09 to $4.38 \mathrm{~kg}] ; P<0.001)$ was significantly increased only in the EXP group. Overall, aerobic exercise at the LT was effective in improving body composition.

As shown in Table 3, a significant interaction was observed between the two groups in $\mathrm{VO}_{2}$ LT $\left(P=0.001, \eta^{2}=0.267\right), \mathrm{VO}_{2 \max }$
$\left(P=0.007, \eta^{2}=0.194\right)$, treadmill speed at HR_LT $(P<0.001$, $\left.\eta^{2}=0.520\right)$, and bicycle load at HR_LT $\left(P<0.001, \eta^{2}=0.311\right)$. Post-hoc analyses found significantly improved $\mathrm{VO}_{2 \max }$ (EXP, 5.41 $\mathrm{mL} / \mathrm{kg} / \mathrm{min}$ [3.17 to $7.65 \mathrm{~mL} / \mathrm{kg} / \mathrm{min}$ ]; CON, $2.14 \mathrm{~mL} / \mathrm{kg} / \mathrm{min}$ [1.27 to $3.02 \mathrm{~mL} / \mathrm{kg} / \mathrm{min}] ; P<0.001)$, treadmill speed at HR_LT (EXP, $1.40 \mathrm{~km} / \mathrm{hr}[1.08$ to $1.72 \mathrm{~km} / \mathrm{hr}]$; CON, $0.29 \mathrm{~km} / \mathrm{hr}[0.09$ to $0.50 \mathrm{~km} / \mathrm{hr}] ; P<0.01$ ), and bicycle load at HR_LT (EXP, $18.62 \mathrm{w}$ [11.85 to $25.38 \mathrm{w}]$; CON, $4.52 \mathrm{w}[1.07$ to $7.97 \mathrm{w}] ; P<0.05) . \mathrm{VO}_{2}$ LT (EXP, $5.74 \mathrm{~mL} / \mathrm{kg} / \mathrm{min}[3.63$ to $7.85 \mathrm{~mL} / \mathrm{kg} / \mathrm{min}]$; $P<0.001$ ) was significantly increased only in the EXP group. Overall, aerobic exercise at the LT was effective in enhancing aerobic performance.

A significant interaction was found between the two groups for mean RR $\left(P=0.010, \eta^{2}=0.179\right)$, SDNN $\left(P=0.020, \eta^{2}=0.149\right)$, $\operatorname{RMSSD}\left(P<0.001, \eta^{2}=0.402\right), \mathrm{TP}\left(P=0.007, \eta^{2}=0.195\right), \operatorname{LF}(P=$ $\left.0.031, \eta^{2}=0.304\right), \operatorname{HF}\left(P=0.017, \eta^{2}=0.156\right)$, and LF/HF $(P=$

Table 3. Aerobic performance before and after training with main analysis of variance results

\begin{tabular}{|c|c|c|c|c|c|c|c|c|c|}
\hline \multirow[b]{2}{*}{ Measure } & \multicolumn{3}{|c|}{$\mathrm{CON}$} & \multicolumn{3}{|c|}{ EXP } & \multicolumn{3}{|c|}{$\eta^{2}(P)$} \\
\hline & Before & After & $\begin{array}{l}\text { Mean change } \\
(95 \% \mathrm{Cl})\end{array}$ & Before & After & $\begin{array}{l}\text { Mean change } \\
(95 \% \mathrm{Cl})\end{array}$ & Time & Group & Interaction \\
\hline $\mathrm{VO}_{2} \mathrm{LT}(\mathrm{mL} / \mathrm{kg} / \mathrm{min})$ & $24.59 \pm 4.50$ & $24.72 \pm 3.28$ & 0.12 (-2.50 to 2.75$)$ & $23.25 \pm 2.98$ & $28.99 \pm 4.00$ & $5.74(3.63 \text { to } 7.85)^{\ddagger}$ & $0.284(0.001)^{\S}$ & $0.065(0.134)$ & $0.267(0.001)^{8}$ \\
\hline $\mathrm{VO}_{2 \max }(\mathrm{mL} / \mathrm{kg} / \mathrm{min})$ & $36.59 \pm 3.52$ & $38.73 \pm 3.69$ & $2.14(1.27 \text { to } 3.02)^{\ddagger}$ & $35.30 \pm 2.25$ & $40.71 \pm 4.64$ & $5.41(3.17 \text { to } 7.65)^{\ddagger}$ & $0.563(0.000)^{\S}$ & $0.003(0.749)$ & $0.194(0.007)^{\S}$ \\
\hline $\begin{array}{l}\text { Treadmill speed at HR_LT } \\
(\mathrm{km} / \mathrm{hr})\end{array}$ & $5.81 \pm 0.68$ & $6.11 \pm 0.80$ & $0.29(0.09 \text { to } 0.50)^{\dagger}$ & $5.53 \pm 0.39$ & $6.93 \pm 0.81$ & $1.40(1.08 \text { to } 1.72)^{\ddagger}$ & $0.718(0.000)^{\S}$ & $0.046(0.211)$ & $0.520(0.000)^{\mathrm{s}}$ \\
\hline Bicycle load at HR_LT (w) & $61.99 \pm 13.58$ & $66.52 \pm 15.65$ & $4.52(1.07 \text { to } 7.97)^{*}$ & $58.22 \pm 11.20$ & $76.83 \pm 14.62$ & $18.62(11.85 \text { to } 25.38)^{\ddagger}$ & $0.549(0.000)^{\S}$ & $0.017(0.448)$ & $0.311(0.000)^{\S}$ \\
\hline
\end{tabular}

Table 4. Autonomic nervous system function before and after training with main analysis of variance results

\begin{tabular}{|c|c|c|c|c|c|c|c|c|c|}
\hline \multirow{2}{*}{ Measure } & \multicolumn{3}{|c|}{$\mathrm{CON}$} & \multicolumn{3}{|c|}{ EXP } & \multicolumn{3}{|c|}{$\eta^{2}(P)$} \\
\hline & Before & After & Mean change (95\% Cl) & Before & After & Mean change $(95 \% \mathrm{Cl})$ & Time & Group & Interaction \\
\hline Mean RR (ms) & $837.35 \pm 97.96$ & $822.31 \pm 92.48$ & $-15.04(-62.94$ to 32.85$)$ & $830.20 \pm 75.14$ & $881.03 \pm 74.02$ & $50.83(33.27 \text { to } 68.39)^{\ddagger}$ & $0.061(0.148)$ & $0.028(0.325)$ & $0.179(0.010)^{\S}$ \\
\hline SDNN (ms) & $35.60 \pm 9.35$ & $35.05 \pm 10.95$ & -0.55 (-5.05 to 3.95$)$ & $34.87 \pm 9.68$ & $39.96 \pm 8.52$ & $5.08(3.22 \text { to } 6.94)^{\ddagger}$ & 0.102 (0.058) & $0.014(0.491)$ & $0.149(0.020)^{\S}$ \\
\hline RMSSD (ms) & $20.87 \pm 6.88$ & $22.74 \pm 7.86$ & $1.87(0.34 \text { to } 3.40)^{*}$ & $20.20 \pm 7.57$ & $26.63 \pm 7.27$ & $6.42(5.12 \text { to } 7.72)^{\ddagger}$ & $0.691(0.000)^{s}$ & $0.013(0.510)$ & $0.402(0.000)^{\S}$ \\
\hline $\mathrm{TP}\left(\mathrm{ms}^{2}\right)$ & $6.82 \pm 0.58$ & $6.92 \pm 0.58$ & $0.10(-0.04$ to 0.24$)$ & $7.02 \pm 0.69$ & $7.36 \pm 0.66$ & $0.34(0.23 \text { to } 0.46)^{\ddagger}$ & $0.445(0.000)^{5}$ & $0.065(0.133)$ & $0.195(0.007)^{\S}$ \\
\hline $\mathrm{LF}\left(\mathrm{ms}^{2}\right)$ & $5.47 \pm 0.60$ & $5.51 \pm 0.63$ & $0.04(-0.11$ to 0.19$)$ & $5.30 \pm 0.63$ & $5.19 \pm 0.70$ & $-0.12(-0.40$ to 0.16$)$ & $0.008(0.607)$ & $0.041(0.236)$ & 0.031 (0.304) \\
\hline $\mathrm{HF}\left(\mathrm{ms}^{2}\right)$ & $5.20 \pm 0.65$ & $5.16 \pm 0.67$ & $-0.04(-0.33$ to 0.25$)$ & $5.14 \pm 1.01$ & $5.46 \pm 0.94$ & $0.32(0.23 \text { to } 0.41)^{\ddagger}$ & $0.100(0.061)$ & $0.006(0.641)$ & $0.156(0.017)^{\S}$ \\
\hline $\mathrm{LF} / \mathrm{HF}$ & $1.06 \pm 0.14$ & $1.07 \pm 0.10$ & $0.01(-0.05$ to 0.07$)$ & $1.05 \pm 0.14$ & $0.96 \pm 0.13$ & $-0.09(-0.14 \text { to }-0.04)^{\dagger}$ & $0.114(0.044)^{5}$ & $0.066(0.129)$ & $0.184(0.009)^{5}$ \\
\hline $\begin{array}{l}\text { Salivary cortisol } \\
(\mu \mathrm{g} / \mathrm{dL})\end{array}$ & $0.27 \pm 0.11$ & $0.35 \pm 0.18$ & $0.08(-0.01$ to 0.16$)$ & $0.31 \pm 0.17$ & $0.29 \pm 0.15$ & $-0.01(-0.11$ to 0.08$)$ & $0.032(0.297)$ & $0.001(0.837)$ & $0.065(0.132)$ \\
\hline
\end{tabular}

Values are presented as mean \pm standard deviation.

${ }^{*} P<0.05 ;{ }^{\dagger} P<0.01 ;{ }^{\ddagger} P<0.001$ vs. before training; ${ }^{\S}$ Significant interaction or main effect.

CON, control group; EXP, experimental group; Cl, confidence interval; SDNN, standard deviation of NN intervals; RMSSD, root mean square of successive differences; TP, total power; LF, low frequency; HF, high frequency. 
$\left.0.009, \eta^{2}=0.184\right)$. However, salivary cortisol did not show significant interaction between the two groups (Table 4). Post-hoc analyses revealed a significant improvement in RMSSD (EXP, $6.42 \mathrm{~ms}$ [5.12 to $7.72 \mathrm{~ms}$ ]; CON, $1.87 \mathrm{~ms}$ [0.34 to $3.40 \mathrm{~ms}$; $P<0.05)$ in both groups. However, mean RR (EXP, 50.83 ms [33.27 to 68.39 $\mathrm{ms}] ; P<0.001)$, SDNN (EXP, $5.08 \mathrm{~ms}[3.22$ to $6.94 \mathrm{~ms}] ; P<0.001)$, TP (EXP, $0.34 \mathrm{~ms}^{2}$ [0.23 to $\left.\left.0.46 \mathrm{~ms}^{2}\right] ; P<0.001\right)$, HF (EXP, $0.32 \mathrm{~ms}^{2}$ [0.23 to $\left.\left.0.41 \mathrm{~ms}^{2}\right] ; P<0.001\right)$ and LF/HF (EXP, -0.09 [-0.14 to $-0.04] ; P<0.01)$ were significantly increased only in the EXP group. The LF did not show a significant difference in either groups. Overall, aerobic exercise at the LT effectively enhanced ANS function.

\section{DISCUSSION}

Aerobic exercise at the LT for 12 weeks was associated with improved body composition, aerobic performance, and ANS function in obese Korean women. The results mean that aerobic exercise at the LT can be a practical and successful obese resolution method.

The dietary intake of both groups showed a significant decrease within time (EXP, $-19.8 \%$; CON, $-15.2 \%$ ) and daily activity was significantly increased (EXP, 6.8\%; CON, 9.6\%). The decrease in dietary intake and the increase in daily activity are thought to be caused by motivation of body weight reduction and health care via participating in the study. ${ }^{23}$ These changes appears to have resulted in body composition and aerobic improvement in the CON group without exercise intervention. However, given the purpose of the study, and because there was no significant difference in dietary intake and daily activity at each time point, we concluded that the difference between the two groups of dependent variables (body composition, aerobic performance, and ANS function) was not affected by dietary intake and daily activity.

Aerobic exercise, the most commonly used obesity treatment, was performed for an extended period of time: three times a week for 60 to 90 minutes. Moderate intensity was most appropriate for exercise intensity, and it has been reported that it is most preferable to set it to the LT. ${ }^{8}$ In a study of changes in body composition according to exercise training using a systematic review and meta-analysis, Wewege et al. ${ }^{25}$ reported that aerobic exercise training of moderate intensity can induce significant reductions in body fat and waist cir- cumference, even in the absence of changes in body weight. Verheggen et al. ${ }^{26}$ reported that a combination of caloric restriction and exercise is effective for weight loss, decreasing visceral fat stores. Ho et al. ${ }^{27}$ reported that moderate exercise intervention increases energy expenditure, promotes fat oxidation, and induces muscle synthesis, thereby increasing muscle mass. They reported significant improvements in body weight $(-1.6 \%), \%$ body fat $(-2.6 \%)$, abdominal fat percentage $(-2.8 \%)$, and cardio-respiratory fitness (13.3\%). In our study, aerobic exercise at the LT induced greater body composition improvements versus controls in women with obesity. It also showed greater changes in body composition (body weight, $-6.4 \%$; BMI, $-6.4 \%$; fat-free mass, $7.6 \%$; and \%body fat, $-13.1 \%$ ) than previous studies. These results indicate that aerobic exercise at the LT may be an efficient component of weight management programs.

Obese individuals typically show a decline in aerobic performance and diverse degrees of dyspnea in association with mechanical abnormalities, increased ventilator requirements secondary to the increased metabolic load, and greater effort in breathing. ${ }^{28}$ Consequently, they may be particularly predisposed to respiratory muscle fatigue during exercise. It is therefore important to improve respiratory and aerobic exercise capacity through the application of aerobic exercise intervention to obese patients. In general, aerobic exercise training is known to enhance aerobic performance via increased capillary density, increased myoglobin content, increased number, size and efficiency of mitochondria, and activation of enzymes associated with oxidative phosphorylation. ${ }^{7,29}$ In our study, $\mathrm{VO}_{2} \_\mathrm{LT}, \mathrm{VO}_{2 \max }$, treadmill speed at HR_LT, and bicycle load at HR_LT were measured using GXT to evaluate aerobic performance. Aerobic exercise at the LT was associated with a greater improvement in all aerobic performance parameters. Aerobic exercise at the LT demonstrates the potential for effective treatment of obesity via increased respiratory, metabolic, and aerobic performance in obese individuals.

HRV testing is an effective method for quantitative evaluation of the activity and balance of the ANS. ${ }^{12} \mathrm{HRV}$ is measured by a noninvasive and relatively simple method, and changes in the activity and balance of the ANS due to stress enable the diagnosis of stressrelated diseases. ${ }^{30}$ Kemp et al. ${ }^{31}$ suggested that depression, panic disorder, anxiety, and obesity affect the ANS imbalance primarily 
by reducing the activity of the PNS. Cortisol, a hormone secreted during stress, is also known to promote senescence. Salivary cortisol represents the sympathetic-parasympathetic balance. ${ }^{12}$ In other words, HRV and salivary cortisol indicate an abnormal function of the ANS and may affect various physiological and clinical parameters while increasing prevalence and mortality. ${ }^{12,20}$ Twelve weeks of aerobic exercise intervention at the LT in women with obesity was associated with a significant improvement in mean RR, SDNN, RMSSD, TP, HF and LF/HF. Among the HRV parameters corresponding to the time domain, mean RR, SDNN, and RMSSD measure the activity of the PNS. ${ }^{12,31}$ SDNN is an indicator of physiological resilience to stress and clinically low SDNN is a predictor of high mortality in cardiovascular disease. ${ }^{32,33}$ RMSSD is closely related to atrial fibrillation, and the larger the RMSSD, the more physiologically healthy and relaxed. ${ }^{32-34} \mathrm{TP}, \mathrm{HF}$, and HF/LF belong to the frequency domain, HRV and HF reflect the activity of the vagus nerve, and TP is an index that reflects the overall control ability of the ANS. ${ }^{34} \mathrm{LF}$ is associated with mental stress and reportedly is significantly positively correlated with depression, anger, and somatization. ${ }^{35}$ Increasing LF reduces the overall HRV function, resulting in greater heart instability. ${ }^{35}$ High LF/HF means that the sympathetic nervous system activity is relatively high or that the parasympathetic activity is suppressed. ${ }^{12}$ Kim et al. ${ }^{12}$ investigated whether a combination of aerobic and resistance exercise administered over a period of 12 weeks enhanced HRV in obese and elderly Korean women. They reported that 12 weeks of combined aerobic and resistance exercise improved HRV, reducing mental stress in obese older women. Likewise, our study confirmed that 12 weeks of aerobic exercise at the LT, although different in exercise intensity and type, enhanced the sympathetic-parasympathetic balance, which is highly correlated with obesity and diseases in women with obesity.

In summary, these results suggest that 12 weeks of aerobic exercise at the LT can be an effective treatment for obesity, enhancing health via improvement of body composition, aerobic performance and ANS function in women with obesity. Based on these findings, further collaborative research involving enhancement of ANS function for obese patients in various countries is needed.

\section{CONFLICTS OF INTEREST}

The authors declare no conflict of interest.

\section{ACKNOWLEDGMENTS}

This work was supported by the Ministry of Education of the Republic of Korea and the National Research Foundation of Korea (NRF-2019S1A5B8099542).

\section{AUTHOR CONTRIBUTIONS}

Study concept and design: HYP, KL; acquisition of data: JK, $\mathrm{HH}$; analysis and interpretation of data: HYP, WSJ; drafting of the manuscript: HYP; critical revision of the manuscript: KL; statistical analysis: WSJ; obtained funding: KL; administrative, technical, or material support: JK, HH; and study supervision: HYP, KL.

\section{REFERENCES}

1. Park HY, Kim J, Park MY, Chung N, Hwang H, Nam SS, et al. Exposure and exercise training in hypoxic conditions as a new obesity therapeutic modality: a mini review. J Obes Metab Syndr 2018;27:93-101.

2. Díaz-Gutiérrez J, Martínez-González MÁ, Pons Izquierdo JJ, González-Muniesa P, Martínez JA, Bes-Rastrollo M. Living at higher altitude and incidence of overweight/obesity: prospective analysis of the SUN cohort. PLoS One 2016;11:e0164483.

3. Chung N, Park HY, Park MY, Hwang YY, Lee CH, Han JS, et al. Association of daily physical activity level with health-related factors by gender and age-specific differences among Korean adults based on the sixth (2014-2015) Korea National Health and Nutrition Examination Survey. J Exerc Nutrition Biochem 2017;21:30-8.

4. Fabbrini E, Klein S. Fundamentals of cardiometabolic risk factor reduction: achieving and maintaining weight loss with pharmacotherapy or bariatric surgery. Clin Cornerstone 2008; 9:41-8.

5. Urdampilleta A, González-Muniesa P, Portillo MP, Martínez JA. Usefulness of combining intermittent hypoxia and physical 
exercise in the treatment of obesity. J Physiol Biochem 2012; 68:289-304.

6. Wu T, Gao X, Chen M, van Dam RM. Long-term effectiveness of diet-plus-exercise interventions vs. diet-only interventions for weight loss: a meta-analysis. Obes Rev 2009;10:313-23.

7. American College of Sports Medicine. ACSM's guidelines for exercise testing and prescription. 9th ed. Baltimore (MD): Lippincott Williams \& Wilkins; 2014.

8. Menzel K, Hilberg T. Blood coagulation and fibrinolysis in healthy, untrained subjects: effects of different exercise intensities controlled by individual anaerobic threshold. Eur J Appl Physiol 2011;111:253-60.

9. Ham JH, Park HY, Kim YH, Bae SK, Ko BH, Nam SS. Development of an anaerobic threshold (HRLT, HRVT) estimation equation using the heart rate threshold (HRT) during the treadmill incremental exercise test. J Exerc Nutrition Biochem 2017; 21:43-9.

10. Wasserman K. The anaerobic threshold measurement to evaluate exercise performance. Am Rev Respir Dis 1984;129:S35-40.

11. Alnasir FA, Masuadi EM. The effect of loss of body weight on lipid profile in overweight individuals. Saudi Med J 2006;27: 687-92.

12. Kim J, Park HY, Lim K. Effects of 12 weeks of combined exercise on heart rate variability and dynamic pulmonary function in obese and elderly Korean women. Iran J Public Health 2018; 47(Suppl 1):74-81.

13. Henriksen EJ. Invited review: effects of acute exercise and exercise training on insulin resistance. J Appl Physiol (1985) 2002;93:788-96.

14. Baylor LS, Hackney AC. Resting thyroid and leptin hormone changes in women following intense, prolonged exercise training. Eur J Appl Physiol 2003;88:480-4.

15. Hagobian TA, Sharoff CG, Stephens BR, Wade GN, Silva JE, Chipkin SR, et al. Effects of exercise on energy-regulating hormones and appetite in men and women. Am J Physiol Regul Integr Comp Physiol 2009;296:R233-42.

16. Rosenwinkel ET, Bloomfield DM, Arwady MA, Goldsmith RL. Exercise autonomic function in health and cardiovascular disease. Cardiol Clin 2001;19:369-87.

17. Lee CM, Wood RH, Welsch MA. Influence of short-term en- durance exercise training on heart rate variability. Med Sci Sports Exerc 2003;35:961-9.

18. Kim MK, Tanaka K, Kim MJ, Matsuo T, Ajisaka R. Exercise training-induced changes in heart rate recovery in obese men with metabolic syndrome. Metab Syndr Relat Disord 2009;7: 469-76.

19. Nagai N, Moritani T. Effect of physical activity on autonomic nervous system function in lean and obese children. Int J Obes Relat Metab Disord 2004;28:27-33.

20. Woo JM, Kim ES, Yoon HY, Choi YH. The relation between heart rate variability and pharmacotherapy in patients with panic disorder. J Korean Neuropsychiatr Assoc 2005;44:342-9.

21. Matsumoto T, Miyawaki C, Ue H, Kanda T, Yoshitake Y, Moritani T. Comparison of thermogenic sympathetic response to food intake between obese and non-obese young women. Obes Res 2001;9:78-85.

22. Poirier P, Hernandez TL, Weil KM, Shepard TJ, Eckel RH. Impact of diet-induced weight loss on the cardiac autonomic nervous system in severe obesity. Obes Res 2003;11:1040-7.

23. Park HY, Kim S, Kim Y, Park S, Nam SS. Effects of exercise training at lactate threshold and detraining for 12 weeks on body composition, aerobic performance, and stress related variables in women with obesity. J Exerc Nutrition Biochem $2019 ; 23: 22-8$.

24. Silva MN, Markland D, Carraça EV, Vieira PN, Coutinho SR, Minderico CS, et al. Exercise autonomous motivation predicts 3-yr weight loss in women. Med Sci Sports Exerc 2011;43: 728-37.

25. Wewege M, van den Berg R, Ward RE, Keech A. The effects of high-intensity interval training vs. moderate-intensity continuous training on body composition in overweight and obese adults: a systematic review and meta-analysis. Obes Rev 2017; 18:635-46.

26. Verheggen RJ, Maessen MF, Green DJ, Hermus AR, Hopman MT, Thijssen DH. A systematic review and meta-analysis on the effects of exercise training versus hypocaloric diet: distinct effects on body weight and visceral adipose tissue. Obes Rev 2016;17:664-90.

27. Ho SS, Dhaliwal SS, Hills AP, Pal S. The effect of 12 weeks of aerobic, resistance or combination exercise training on cardio- 
vascular risk factors in the overweight and obese in a randomized trial. BMC Public Health 2012;12:704.

28. Chlif M, Chaouachi A, Ahmaidi S. Effect of aerobic exercise training on ventilatory efficiency and respiratory drive in obese subjects. Respir Care 2017;62:936-46.

29. Wong PC, Chia MY, Tsou IY, Wansaicheong GK, Tan B, Wang $\mathrm{JC}$, et al. Effects of a 12-week exercise training programme on aerobic fitness, body composition, blood lipids and C-reactive protein in adolescents with obesity. Ann Acad Med Singapore 2008;37:286-93.

30. Dulleck U, Ristl A, Schaffner M, Torgler B. Heart rate variability, the autonomic nervous system, and neuroeconomic experiments. J Neurosci Psychol Econ 2011;4:117-24.

31. Kemp AH, Quintana DS, Felmingham KL, Matthews S, Jelinek
HF. Depression, comorbid anxiety disorders, and heart rate variability in physically healthy, unmedicated patients: implications for cardiovascular risk. PLoS One 2012;7:e30777.

32. Dash S, Chon KH, Lu S, Raeder EA. Automatic real time detection of atrial fibrillation. Ann Biomed Eng 2009;37:1701-9.

33. DeGiorgio CM, Miller P, Meymandi S, Chin A, Epps J, Gordon $S$, et al. RMSSD, a measure of vagus-mediated heart rate variability, is associated with risk factors for SUDEP: the SUDEP-7 Inventory. Epilepsy Behav 2010;19:78-81.

34. Park KJ, Jeong H. Assessing methods of heart rate variability. Korean J Clin Neurophysiol 2014;16:49-54.

35. Perciaccante A, Fiorentini A, Valente R, Granata M, Tubani L. Migraine and heart rate variability. Arch Intern Med 2007;167: 2264. 